\title{
Surgical management of World Health Organization Grade II gliomas in eloquent areas: the necessity of preserving a margin around functional structures
}

\author{
Santiago Gil-Robles, M.D., ${ }^{1}$ and Hugues Duffau, M.D., Ph.D. ${ }^{2,3}$ \\ ${ }^{1}$ Department of Neurosurgery, Hospital Quiron, Madrid, Spain; ${ }^{2}$ Department of Neurosurgery, \\ Hôpital Gui de Chauliac; and ${ }^{3}$ Institut of Neuroscience of Montpellier, Institut National de la Santé et de la \\ Recherche Médicale Unité 583, Plasticity of Central Nervous System, Human Stem Cells and Glial Tumors, \\ Hôpital Saint Eloi, Centre Hospitalier Universitaire Montpellier, France
}

Object. Recent surgical studies have demonstrated that the extent of resection is significantly correlated with median survival in WHO Grade II gliomas. Consequently, thanks to advances in intraoperative functional mapping, the authors questioned whether it is actually necessary to leave a "security" margin around eloquent structures.

Methods. The authors first reviewed the classic literature, especially that based on epilepsy surgery and functional neuroimaging techniques, which led them to propose the rule of a security margin. Second, they detailed new developments in the field of intrasurgical electrical mapping, especially with regard to subcortical stimulation of the projection and long-distance association pathways. On the basis of these advances, the removal of gliomas according to functional boundaries has recently been suggested, with no margin around eloquent structures.

Results. Comparative results showed that the rate of permanent deficit was similar with or without a security margin, that is, $<2 \%$. However, a higher rate of transient neurological worsening in the immediate postsurgical period was associated with the absence of a margin, with recovery following adapted rehabilitation. On the other hand, the extent of resection was in essence improved with no margin.

Conclusions. This no-margin technique, based on the subpial dissection, and the repetition of both cortical and subcortical stimulation to preserve eloquent cortex as well as the white matter tracts (U-fibers, projection pathways, and long-distance connectivity) allow optimization of the extent of resection while preserving the quality of life (despite transitory impairment) thanks to mechanisms of brain plasticity. (DOI: 10.3171/2009.12.FOCUSO9236)

$\begin{array}{llcl}\text { KEY WoRDS } & \bullet \text { awake surgery } & \bullet & \text { direct electrical stimulation } \\ \text { intraoperative functional mapping } & \bullet & \text { low-grade glioma } \bullet \text { eloquent area }\end{array}$

$\mathrm{D}$ URING the past decade, the surgical management of WHO GIIGs has dramatically changed. The modification in strategies focused mainly on 2 points: 1) oncological considerations, with an optimization of the EOR to increase overall patient survival; and 2) functional considerations, with a minimization of postoperative morbidity and preservation of the quality of life.

Indeed, on the basis of objective control MR imaging of the glioma removal, recent surgical studies have demonstrated that the EOR was significantly correlated with overall survival. ${ }^{4,10,20,47,66,70}$ As a consequence, surgery is the first therapeutic option in GIIGs. ${ }^{13}$

This more aggressive surgical attitude should nonetheless avoid permanent functional worsening. Usually,

Abbreviations used in this paper: $\mathrm{DT}=$ diffusion tensor; EOR = extent of resection; fMR = functional MR; GIIG = Grade II glioma; $\mathrm{MEG}=$ magnetoencephalography.
GIIGs are diagnosed after a seizure in young patients with no or only mild neurological deficits,,$^{23,58,59}$ despite the frequent involvement of so-called eloquent areas and progressive diffusion along functional subcortical pathways. ${ }^{24}$ Such functional compensation is attributable to brain plasticity mechanisms made possible by the slow growth of GIIGs, with the recruitment of perilesional and/or remote (ipsi- or contralateral) areas..$^{11}$ Therefore, the identification and preservation of these compensatory areas throughout the resection is crucial.

For these reasons, intraoperative electrostimulation mapping is increasingly used by neurosurgeons to optimize the benefit/risk ratio of surgery. ${ }^{1-6,8,14,17,20,25,69}$ This technique has progressively evolved since the pioneers ${ }^{55-58}$ who first applied it in epilepsy surgery. Over decades, several authors have contributed to its development, especially Ojemann and colleague ${ }^{49-53}$ and Berger and associates, ${ }^{4,5}$ who began to use direct corticosubcortical stimulations in oncology in the early 1990s. At that 
time, they proposed that a "security" margin should be maintained around positive stimulation sites, especially language sites, to minimize the risk of a permanent deficit. ${ }^{33}$ Moreover, advances in preoperative functional neuroimaging techniques and the incorporation of these data into a neuronavigational system (so-called functional neuronavigation) have widely contributed to the concept of this security margin around "activated areas." $35,42,69,73$

Interestingly, although white matter pathways have received less interest for a long time, subcortical connectivity has recently been studied by a growing number of investigative teams. This attitude is in part attributable to the newly developed method of tractography with DT imaging, which allows noninvasive visualization of the main bundles in vivo. ${ }^{9}$ A revival of the fiber dissection technique on cadavers has also occurred to foster a better understanding of the anatomy of the white matter pathways and to validate DT imaging. ${ }^{28,45,61}$ In this context, some authors have proposed the regular use of intraoperative electrostimulation during glioma surgery to map not only the cortex but also the subcortical tracts. ${ }^{1,2,6,8,14,17,23}$ The goal was to study the function of the different (somatosensory, motor, visuospatial, and language) pathways to continue the resection until these bundles are encountered. ${ }^{23}$ Indeed, it has been shown that the preservation of subcortical connectivity is crucial to allow for the efficiency of brain plasticity mechanisms: in cases of white matter injury, the risk of inducing a permanent deficit with no functional recovery is very high. ${ }^{12}$ Thus, online detection of these tracts by using subcortical electrostimulation mapping at the end of glioma removal is essential to preserve normal brain processing. On the other hand, to improve the EOR, tumor removal should not be interrupted before contact with these pathways..$^{14}$

On the basis of these new oncological and functional insights into GIIG surgery, the aim of our review was to raise the question of whether it is actually necessary to leave a security margin around eloquent structures.

\section{The Principle of a Security Margin}

It is now widely accepted that one cannot localize functional areas, especially language sites, by solely relying on anatomical landmarks. Since the seminal works of Ojemann et al. ${ }^{49}$ using cortical electrostimulation, it has been shown that language networks are underlain by a mosaic of distributed epicenters with great intersubject variability. Therefore, a maximal resection with minimal risks requires individual extra- or intraoperative brain mapping, a technique initially developed mainly for epilepsy surgery. ${ }^{49,51}$ Extraoperatively, cortical stimulations were performed using subdural grids, generally with contacts spaced $10 \mathrm{~mm}$ apart. As a consequence, a margin of $\sim 1 \mathrm{~cm}$ was typically preserved around functional sites. Intraoperatively, Ojemann and colleagues described putting sterile tags on the brain surface, spaced $\sim 1 \mathrm{~cm}$ apart, before performing electrical mapping, which consisted of testing each site marked by a tag. When they applied this method to tumor surgery, these same authors recommended preserving an equivalent margin of $\sim 7$ to $10 \mathrm{~mm}$ around the positive stimulations sites. ${ }^{33,65,67}$ Since this study, the principle of a security margin has been integrated by many teams into the surgical technique of brain mapping for tumor surgery. $8,65,67,68$

The progressive development of noninvasive functional neuroimaging techniques of cortical mapping, such as fMR imaging and MEG, also had an important role in reinforcing the principle of a security margin..$^{32,37,60}$ Indeed, it was demonstrated that functional neuroimaging as opposed to direct corticosubcortical stimulations - was not accurate enough, with modifications in the spatial location of activations when repeated acquisitions were performed in the same patients over time ${ }^{34}$ Moreover, many teams have compared fMR imaging with intraoperative electrophysiology $27,29,40,63$ and have shown that the reliability of functional neuroimaging was only between 60 and $90 \%,{ }^{63}$ especially for language functions using both naming and verbal tasks, and thus alone is insufficient to rely on for brain surgery. In addition, these data can be integrated into a neuronavigational system ${ }^{35,48,64,73}$ but with the risk of brain shift throughout the resection. Taking into account these numerous limitations, all authors have agreed to keep a security margin of at least 5-10 $\mathrm{mm}$ around the activation sites provided by presurgical functional neuroimaging to safely achieve lesion removal. Furthermore, it has been proposed that a significant predictor of new neurological deficits is a lesion-to-activation site distance of $<5 \mathrm{~mm} .{ }^{38}$

Finally, fMR imaging and MEG do not provide any information about the white matter pathways, although it is currently understood that subcortical damage is associated with a high risk of severe and permanent neurological deficits. ${ }^{15}$ To overcome this drawback, the new technique of fiber tracking with DT imaging has been widely integrated into presurgical planning in the past few years. Indeed, DT imaging noninvasively provides anatomical information about the white bundles and their relationships to the tumor. ${ }^{9}$ Nonetheless, recent studies have shown that this method is not yet reliable enough, with different results of tracking provided according to the biomathematical model and software used. ${ }^{7}$ Therefore, as reported at the cortical level with regard to fMR imaging and MEG, the correlations between DT imaging and intraoperative electrophysiology at the subcortical level have shown that the fiber tracking technique should be improved before it can be considered as a standard in defining the boundaries of a tumor resection. ${ }^{39}$ As a consequence, several authors have again suggested keeping a margin around the pathways identified using DT imaging and incorporated into a neuronavigational system. ${ }^{35}$

In summary, on the basis of converging evidence provided by both (extra- and intraoperative) electrophysiological and neuroimaging techniques, the principle of a security margin became actual dogma. In this paper, we question whether this rule applies in tumor surgery, especially surgeries concerning infiltrating WHO GIIGs.

\section{Resection With No Margin According to Intrasurgical Cortical and Subcortical Functional Boundaries}

With the aim of improving the EOR, for many years 
TABLE 1: Clinical, radiological, and surgical characteristics in 162 patients who underwent surgery for a WHO GIIG in the left dominant hemisphere*

\begin{tabular}{|c|c|c|c|c|c|c|}
\hline $\begin{array}{c}\text { Glioma Location } \\
\text { (no. of patients) }\end{array}$ & $\begin{array}{l}\text { Preop Examination } \\
\text { (no. of patients) }\end{array}$ & $\begin{array}{l}\text { Preop KPS Score } \\
\text { (no. of patients) }\end{array}$ & $\begin{array}{l}\text { Rate of Immediate } \\
\text { Postsurgical Deficit }\end{array}$ & $\begin{array}{c}\text { Delayed Postop Examination } \\
>3 \text { Mos (no. of patients) }\end{array}$ & $\begin{array}{l}\text { Postop KPS Score } \\
\text { (no. of patients) }\end{array}$ & $\begin{array}{l}\text { Extent of } \\
\text { Resection }\end{array}$ \\
\hline $\begin{array}{l}\text { frontal (85) } \\
\quad \text { F1 (41) } \\
\text { F2 (23) } \\
\text { F3 (21) }\end{array}$ & $\begin{array}{l}\text { normal (78) } \\
\text { language deficits (7) }\end{array}$ & $\begin{array}{c}100(48) \\
90(30) \\
80(7)\end{array}$ & 96 & $\begin{array}{l}\text { normal (83) } \\
\text { language deficit (2)† }\end{array}$ & $\begin{array}{r}100(39) \\
90(44) \\
80(2)\end{array}$ & $\begin{array}{l}32 \mathrm{~T} \\
41 \mathrm{ST} \\
12 \mathrm{P}\end{array}$ \\
\hline temporal (25) & $\begin{array}{l}\text { normal (22) } \\
\text { language deficits (3) }\end{array}$ & $\begin{array}{r}100(12) \\
90(10) \\
80(3)\end{array}$ & 89 & $\begin{array}{l}\text { normal (24) } \\
\text { language deficit (1)† }\end{array}$ & $\begin{array}{r}100(11) \\
90(13) \\
80(1)\end{array}$ & $\begin{array}{l}10 \mathrm{~T} \\
13 \mathrm{ST} \\
2 \mathrm{P}\end{array}$ \\
\hline paralimbic (27) & $\begin{array}{l}\text { normal (23) } \\
\text { language deficits (4) }\end{array}$ & $\begin{array}{r}100(13) \\
90(10) \\
80(4)\end{array}$ & 60 & $\begin{array}{l}\text { normal (24) } \\
\text { language deficit (3) } \\
\text { new deficits }(2) \ddagger\end{array}$ & $\begin{array}{l}100(14) \\
90(8) \\
80(3) \\
70(2)\end{array}$ & $\begin{array}{c}6 \mathrm{~T} \\
12 \mathrm{ST} \\
9 \mathrm{P}\end{array}$ \\
\hline POTJ (10) & $\begin{array}{l}\text { normal (9) } \\
\text { language deficit (1) }\end{array}$ & $\begin{array}{r}100(5) \\
90(4) \\
80(1)\end{array}$ & 90 & normal (10) & $\begin{array}{r}100(4) \\
90(6)\end{array}$ & $\begin{array}{l}4 \mathrm{~T} \\
5 \mathrm{ST} \\
1 \mathrm{P}\end{array}$ \\
\hline
\end{tabular}

* F1 = superior frontal gyrus; F2 = middle frontal gyrus; F3 = inferior frontal gyrus; KPS = Karnofsky Performance Scale; $P=$ partial; $P O T J=$ parietooccipitotemporal junction; ST = subtotal; $T$ = total.

$\dagger$ From the patients with preoperative deficits.

$\ddagger$ New deficits occurred in 2 of the 3 patients with language deficits.

we have proposed the resection of GIIGs in functional areas $^{14}$ without leaving any margin around the positive stimulation sites intraoperatively identified using both cortical and subcortical electrical mapping. Summarized in Table 1 are the clinical and radiological characteristics of 162 patients who underwent surgery and corticosubcortical stimulations for WHO GIIGs in the dominant hemisphere without any margin. This surgical strategy is based on several principles.

\section{Cortical Subpial Dissection}

In all cases, independent of preoperative data provided by functional neuroimaging methods-used mainly as a baseline to study the mechanisms of plasticity on an individual scale rather than as a technique for delineating resection boundaries ${ }^{19,62}$-we performed intraoperative cortical electrostimulation mapping before any tumor removal. This method, including the electrical parameters and intraoperative clinical tasks, has been described in detail elsewhere. ${ }^{42}$ Briefly, a bipolar electrode with tips spaced $5 \mathrm{~mm}$ apart and delivering a biphasic current (pulse frequency $60 \mathrm{~Hz}$, single pulse phase duration 1 msec, and amplitude 2-8 mA under local anesthesia and 2-16 $\mathrm{mA}$ under general anesthesia exclusively for motor mapping near the pyramidal structures in the nondominant hemisphere) was applied to the brain. When this surface mapping revealed crucial site(s) immediately near a sulcus, the other side of the sulcus was used to perform a subpial dissection in direct contact with the eloquent area(s). It means that no margin was left, except the sole protection represented by the 2 layers of pia and the vessels preserved within the depth of the sulcus-so minimizing the risk of ischemia within the eloquent structures even if they constituted the edge of the surgical cavity, because they were covered by the pia mater. It is worth noting, however, that the cortex buried within the nonfunctional side of the sulcus as well as the U-fibers coming from this cortex should be mapped online throughout the resection before removing it. Interestingly, such mapping cannot be performed if only extraoperative mapping using cortical grids has been decided on or if the resection is based on fMR imaging studies alone, which is unable to differentiate activated areas on the surface cortex from those buried within the sulcus by using the blood oxygen level-dependent (BOLD) effect. Therefore, this technique of subpial dissection with online cortical and subcortical (U-fibers) mapping provides more accurate functional data than the methods typically described in the literature (Figs. 1 and 2).

\section{Intragyral Resection With Mapping of the Subcortical Projection Fibers}

After cortical surface mapping, when there is no sulcal limit between the positive stimulation site(s) and the tumor, the resection is pursued within the gyrus in contact with the crucial zone(s). Such resection with no security margin is made possible thanks to 2 intraoperative techniques. First, at the cortical level, we used a probe and not grids, meaning that we can perform multiple stimulations by slightly moving the probe from 1 to $2 \mathrm{~mm}$ and/ 


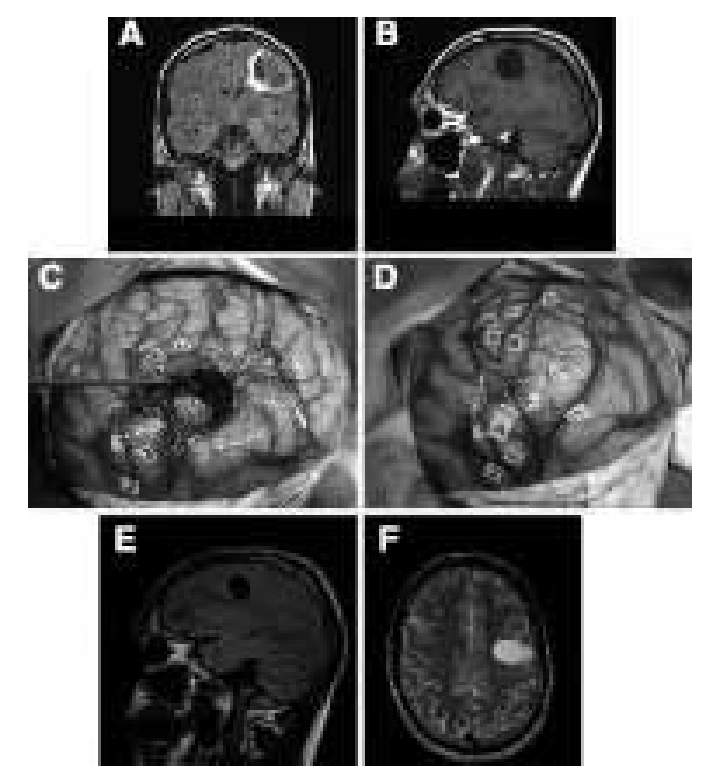

FIG. 1. Preoperative coronal FLAIR (A) and sagittal T1-weighted (B) MR images showing a left precentral glioma involving the middle frontal gyrus. Intraoperative photographs (C and D) of cortical mapping: tags $A, B$, and $C$ are tumor boundaries, as shown by intraoperative ultrasonography. Numbers 1,2 , and 3 indicate the primary motor area of the hand; 4, speech arrest with facial movements; and 5 and 6 , speech arrest in the ventral premotor cortex. Subcortical mapping (D) showing the resection cavity with no margin between function and tumor, thanks to a subpial dissection along the precentral sulcus (spatula). The subcortical functional boundaries were the pyramidal fibers tract of the hand at the bottom of the sulcus (Number 37) and fibers coming from ventral premotor cortex inducing anarthria (Number 36) -both constituting the so-called projection fibers vertical connectivity-as well as phonemic paraphasia elicited by stimulation over the arcuate fasciculus, that is, long-distance association pathways or deep connectivity, or horizontal connectivity (Number 34). Postoperative coronal T2-weighted MR image $(E)$ demonstrating the surgical cavity, which is directly in contact with the precentral sulcus where the subpial dissection was performed, with no residual tumor at this level and no margin. Sagittal FLAIR MR image (F) showing the inferior limit of the surgical cavity directly in contact with the arcuate fasciculus, which lies just above the insula.

or by changing its orientation (parallel or perpendicular to the main axis of the gyrus). As a consequence, even if the space between the electrodes is fixed $(5 \mathrm{~mm})$, it is nevertheless possible to increase the spatial resolution of the functional mapping $\sim 1 \mathrm{~mm}$-that is, the size of each electrode. Interestingly, we did not put a priori sterile tags on the cortex every 5-10 $\mathrm{mm}$, as described by Ojemann et al., ${ }^{49}$ but we did mark a cortical zone if reproducible transient disturbances were elicited by repeated stimulations. Thus, once again, this method allowed better accuracy by identifying the exact spatial delineations of each eloquent area and not its epicenter exclusively. In addition, throughout the resection, we continued to perform repeated stimulations, not only at the cortical level but also at the subcortical level. Indeed, we have shown that realtime converging information between functional mapping of the cortex and its subcortical projection fibers enables us to perform glioma removal until the functional boundaries have been encountered, with no margin..$^{23}$ Thanks to

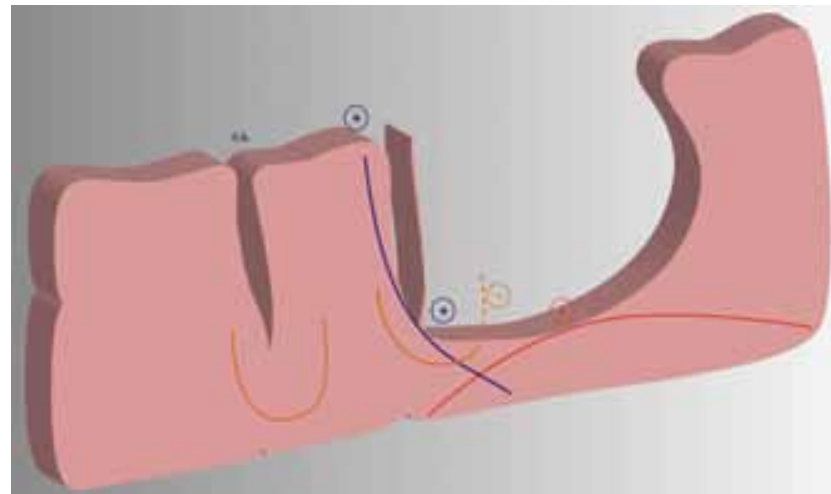

Fıg. 2. Schematic showing removal of a precentral tumor without leaving any margin and using subcortical functional boundaries. Using a subpial dissection along a functional sulcus (for example, the precentral sulcus), fibers coming from the cortex are found at the bottom of it (the projection fibers, that is, vertical connectivity, blue line and plus sign), where the resection is stopped. In addition, U-fibers are mapped throughout the resection (orange lines and minus sign). The horizontal connectivity, namely the long-distance association fibers, are the other subcortical functional boundaries in the depth, for example, arcuate fasciculus (red line and plus sign) at the bottom of the cavity.

online feedback provided by awake patients performing adapted tasks controlled by a speech therapist during the entire resection, language as well as somatosensory and visuospatial functions can be tested (Figs. 3 and 4). ${ }^{14}$

Subcortical Stimulation: Mapping of the Deep Connectivity and Long-Distance Association Pathways

We also applied the same principle of online electrical mapping with regard to the deep connectivitythat is, functional identification, throughout the glioma removal, of the long-distance white matter association pathways (so-called horizontal connectivity) ${ }^{15}$ as well as the gray nuclei. ${ }^{31}$ For instance, we showed that real-time anatomofunctional correlations allow for the reliable detection and preservation of the superior longitudinal fasciculus in the dominant hemisphere, eliciting reproducible phonemic paraphasia when stimulated ${ }^{24}$ the lateral part of the left superior longitudinal fasciculus, inducing speech apraxia during stimulation; ${ }^{22}$ the left occipitofrontal fasciculus, generating semantic paraphasia when stimuated; ${ }^{21}$ the posterior part of the left inferior longitudinal fasciculus, eliciting visual paraphasia during stimulation $;^{41}$ the right superior longitudinal fasciculus, generating hemineglect during stimulation; ${ }^{72}$ or even the left deep gray nuclei, eliciting preservation (caudate) and anarthria (putamen) when stimulated. ${ }^{31}$ Interestingly, such an extensive resection until subcortical functional limits have been encountered also means that there is no rationale for maintaining a cortical security margin. Indeed, if a tumor removal is subcortically pursued in direct contact with the eloquent pathways, even if a cortical margin is preserved around the functional cortex, the projection fibers arising from this cortical security margin will in essence be cut underneath, because they will not respond to stimulation. Thus, all the infiltrated cortical tissue preserved as a security margin will be completely disconnected and without any possibility of 


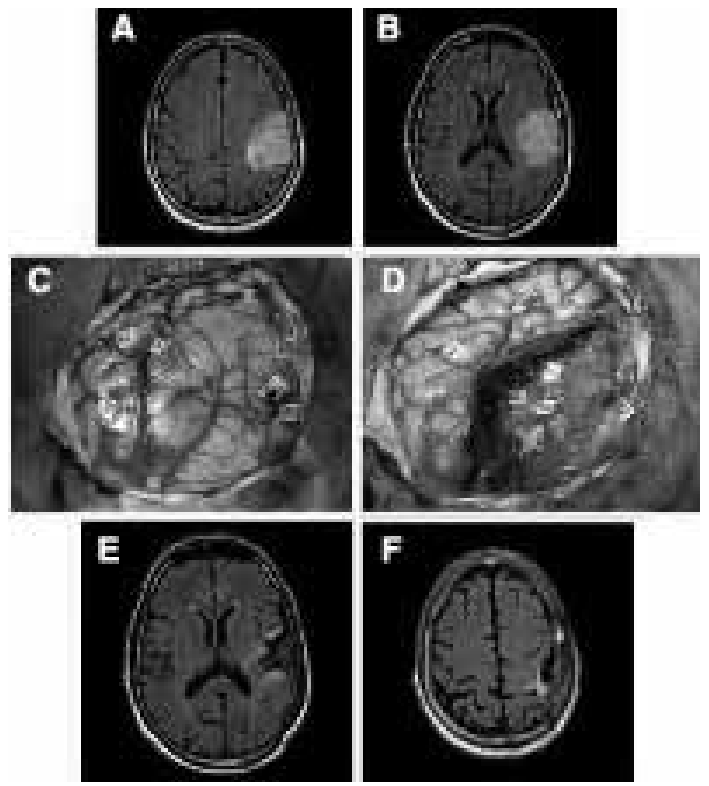

FIG. 3. Preoperative axial FLAIR MR images (A and B) showing a low-grade glioma involving the left inferior parietal lobule as well as the retrocentral gyrus. Intraoperative photograph (C) of cortical mapping: letters show the tumor limits as indicated by ultrasonography. Moreover, electrostimulation identified the primary motor cortex of the face inducing facial movements (Number 46) as well as the region eliciting speech arrest (ventral premotor cortex, Number 8). Anomia was also generated by stimulation over the posterior third of the superior temporal gyrus (Wernicke Area, Number 47). Intraoperative photograph (D) of the surgical cavity, with no margin around the eloquent regions, showing the subpial dissection all along the central sulcus and the sylvian fissure (anteroinferior margin). Thus, we removed the retrocentral gyrus that did not respond to stimulation. In addition, the subcortical functional boundaries, pyramidal fibers of the face (projection fibers, Number 48), arcuate fasciculus generating phonemic paraphasias (Number 49), and the frontoparietal articulatory loop generating dysarthria (Number 50) - both constituting the long-distance association pathways or deep connectivity-represented the subcortical functional boundaries of the resection. Postoperative axial FLAIR MR images (E and F) showing removal of the retrocentral gyrus and inferior parietal lobule. The surgical cavity came in contact with the central sulcus without any margin (subpial dissection) as well as with the arcuate fascicle.

participating in cerebral processing. Therefore, its preservation is not justified, because it would be functionally useless (Figs. 3 and 4).

\section{Results With and Without Preservation of a Security Margin}

A comparison of results between studies utilizing the margin rule and those not is difficult because of their heterogeneity. Nonetheless, some differences can be pointed out (Table 1).

\section{Oncological Considerations}

We have reported that GIIGs can be considered as ellipsoids, and thus that it is possible to calculate the approximate volume of the tumor by applying the formula $4 / 3 \pi^{3}$, that is, the product of the 3 main diameters divided by $2 .{ }^{43,44} \mathrm{We}$ also showed that in our extensive and homogeneous series of GIIGs, the mean lesion volume after diagnosis and before surgery was around $60 \mathrm{ml} .^{14,20}$ Interestingly, by using the formula described above, the mean diameter for a volume of $60 \mathrm{ml}$ is $\sim 4.9 \mathrm{~cm}$. If a security margin of $1 \mathrm{~cm}$ is preserved during surgery, the estimated residual volume would be $60-3.9^{3} / 2=30 \mathrm{ml}$. In other words, in the classic literature, it was usual to speak in terms of distance rather than volume, and thus, there was an underestimation of the postoperative residual tumor. Indeed, leaving a $10-\mathrm{mm}$ margin for a tumor measuring $60 \mathrm{ml}$ means that only half of the lesion would actually be removed. As a consequence and on the basis of a recent oncological series demonstrating a significant correlation between the EOR of the GIIG and overall survival (see above), our proposal to perform resection with no security margin allows clear improvement in the EOR and thus its impact on the natural history of a GIIG.

\section{Functional Results}

Postoperative Permanent Deficit. When comparing the rate of permanent neurological deficits between studies in which patients underwent surgery with cortical and subcortical functional boundaries but without a margin, and those in which a margin was preserved, no differences were observed: $1.7 \%$ without a $\operatorname{margin}^{14}$ and $1-2.5 \%$ with a margin. ${ }^{33,67}$ These similar results confirm that surgery performed without a security margin is a safe technique that does not increase the rate of long-term morbidity. The data also support the fact that surgery for GIIGs in eloquent areas performed under direct electrostimulation to preserve function, with or without a margin, represents a reliable tool for minimizing the risks of permanent deficits.

Postoperative Transient Deficit. We must acknowledge that the rates of transient deficits in the immediate postoperative period are very different. Data from recent surgical series of GIIGs in eloquent areas with no preservation of a security margin showed transitory worsening following resection in almost all patients..$^{14}$ Nonetheless, it is worth noting that at 3 months postsurgery, after an intensive speech and motor reeducation program, all patients recovered except $1.7 \%$, who still experienced a functional deficit. In contrast, in a surgical series of GIIGs in which a $10-\mathrm{mm}$ margin was preserved, only $22^{67}$ to $60 \%{ }^{33}$ of patients had an immediate postoperative language deficit. These same results have been reported for motor function. ${ }^{36}$ For instance, Carrabba et al. ${ }^{8}$ recently used cortical and subcortical mapping for tumors of the rolandic region in 146 patients. These authors indicated that when motor tracts were identified subcortically, new postoperative deficits were evident in $59.3 \%$ of patients, while they were observed in only $14.5 \%$ when motor pathways were not detected intraoperatively. Interestingly, these deficits were permanent in only $6.5 \%$ of the patients, leading the authors to conclude that they were due to transient edema and not an actual brain injury. Indeed, the higher rate of impairment with the no-margin technique is a clear consequence of the technique itself-meaning that the price one pays for a more extensive resection is an immediate postsurgical worsening lasting several weeks in almost all patients. Of course, this point should be extensively 

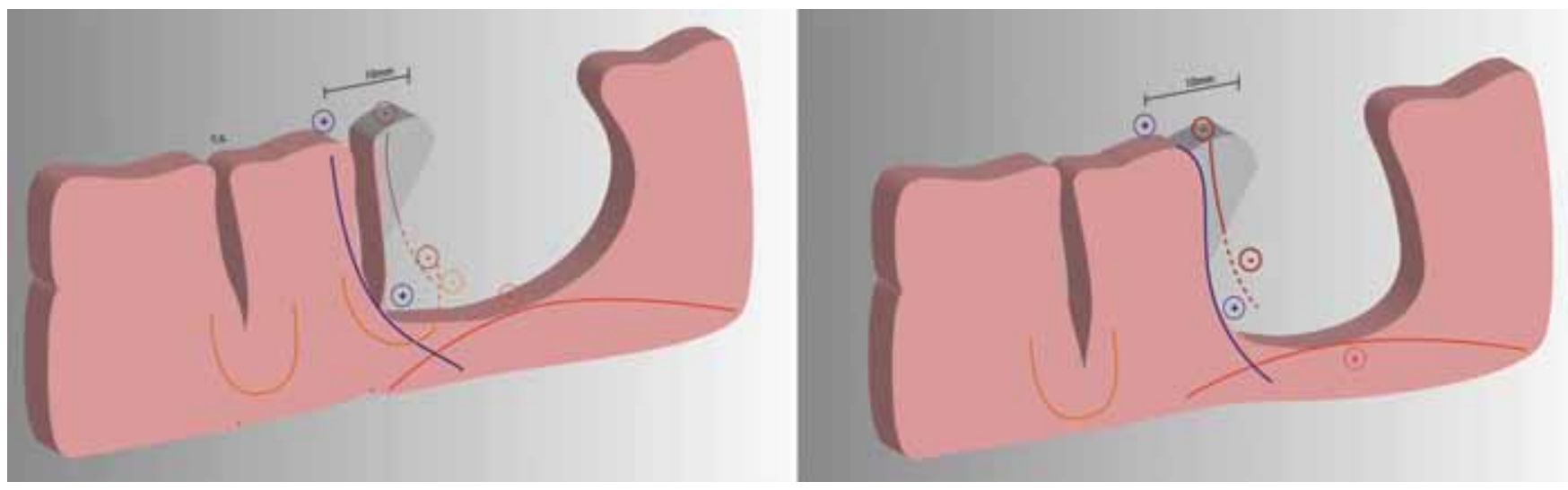

FIG. 4. Schematic showing 2 examples of a resection with a margin. First, a tumor coming into contact with a sulcus (left) removed by leaving a $10-\mathrm{mm}$ security margin from the positive cortical stimulation site (that is, with no subpial dissection; blue line and plus sign). If subcortical stimulation is performed, the projection fibers' vertical connectivity will be identified at the bottom of the sulcus (for example, pyramidal tracts; blue line and plus sign). The U-fibers coming from the other side of the sulcus will also be tested throughout the resection (orange lines and minus sign). At the bottom of the cavity, the horizontal connectivity or long-distance association fibers (for example, the arcuate fasciculus) will represent the deep functional subcortical boundary (red line and plus sign). Interestingly, the cortex invaded by the tumor (gray) is functionally useless, since the resection has been pursued until the subcortical pathways have been encountered (blue and red lines and plus signs). Thus, the fibers arising from this cortex have been disrupted, as they do not respond to stimulation (brown line and minus sign). As a consequence, this cortex was disconnected and can therefore be removed with no functional risk. Schematic (right) showing the same example in the case of an intragyral dissection, without a sulcus.

discussed with the patient and his or her family before any surgery. Moreover, we suggest that an intensive functional reeducation program represents a valuable adjunct for allowing complete recovery, by guiding cerebral plasticity. ${ }^{19,71}$

\section{Brain Plasticity: an Explanation of Recovery After Resection Without a Margin}

To explain this transient worsening followed by functional recovery, we have proposed the principle of a dynamic (not fixed) anatomofunctional organization of the CNS, in large-scale parallel corticosubcortical distributed networks (not in discrete areas) - that is, the concept of a hodological and plastic brain. ${ }^{15,16}$ This type of organization offers the brain the possibility of recruiting perilesional and/or remote (ipsi- and/or contralesional) regions enabling functional compensation, at least when no essential structures detected by intraoperative stimulation are damaged. ${ }^{17}$ This plasticity can occur "online" during surgery $^{26}$ or can take longer, as regularly observed during reoperations in patients with a recurrent GIIG after an incomplete tumor resection for functional reasons: a reshaping was frequently found when comparing 2 mappings spaced by several years. ${ }^{46}$ The slow-growing slope of GIIGs ( $4 \mathrm{~mm} /$ year, on average), ${ }^{44}$ in contrast to acute brain lesions such as stroke or high-grade glioma, can induce this kind of progressive cerebral redistribution in which there is no time for the functional network to compensate for the deficit. ${ }^{11}$ Moreover, this long-term remapping can be studied pre- and postoperatively through repeated noninvasive fMR imaging performed over time during the patient follow-up. Such a strategy opens the door to a multistage surgical approach, optimizing the benefit/risk ratio of the radical resection of GIIGs within eloquent areas. ${ }^{31}$ We must nevertheless insist that when dealing with higher-grade gliomas invading functional areas, one should be more cautious in preserving the quality of life, because the plastic potential of the brain is lower given the rapid growth of the tumor. ${ }^{11}$ Furthermore, because of the shorter median survival, it seems more questionable to generate even a transient deficit lasting several weeks, and thus, it is more questionable not to leave a security margin-in contrast to GIIG.

Interestingly, beyond GIIG, a dynamic view of cerebral organization has also been reported by other authors in epilepsy surgery. ${ }^{54}$ When asking awake patients to perform verb-generation tasks involving novel versus practiced lists during direct brain stimulation, such authors have noted that cortical areas that responded to stimulation in both cases were not concordant. They hypothesized that the cortical regions devoted to a particular task had decreased involvement as the task was learned. The authors concluded that the learning process may explain this modification of the language network. Thus, intensive language rehabilitation after surgery could be underlain by quite similar pathophysiological mechanisms of brain reshaping as compared with those subserving the learning process. ${ }^{18}$ In addition, Ojemann and colleagues ${ }^{54}$ also stated that when comparing the results of language mapping during object-naming versus verb-generation tasks, both functions showed a spatial dissociation in their respective cortical representations, but usually in the range of $10 \mathrm{~mm}$. These findings may constitute another explanation for the higher rate of transient language impairment when no margin is maintained, depending on the functional tasks performed before, during, and after surgery as well the kind of rehabilitation, which should be adapted to each patient. ${ }^{30,71}$ 


\section{Conclusions}

Surgical removal of GIIGs in eloquent areas can be safely accomplished with no security margin around the functional structures and without increasing the rate of permanent deficits thanks to the use of intraoperative mapping in awake patients. This no-margin techniquebased on the subpial dissection and the repetition of both cortical and subcortical stimulations to preserve eloquent cortex as well as the white matter tracts (U-fibers, projection fibers, and long-distance connectivity)-allows optimization of the EOR, and thus an increased impact on the natural history of the tumor, while preserving and even improving the quality of life.

Nevertheless, this method implies a higher rate of immediate postoperative worsening, even if patients completely recover within the 3 months following surgery thanks to an intensive and adapted functional (especially speech) rehabilitation program. It is also worth noting that if cerebral plasticity is induced by the slowgrowing curve of GIIGs and thus explains the postsurgical functional recovery after a resection with no margin, caution must be recommended because the brain's plastic potential is reduced-and the chances of (rapidly) recovering after a radical resection with no security margin in eloquent regions is clearly decreased.

\section{Disclosure}

The authors report no conflict of interest concerning the materials or methods used in this study or the findings specified in this paper.

Author contributions to the study and manuscript preparation include the following. Conception and design: S Gil-Robles, $\mathrm{H}$ Duffau. Acquisition of data: S Gil-Robles, H Duffau. Analysis and interpretation of data: S Gil-Robles, H Duffau. Drafting the article: S Gil-Robles, H Duffau. Critically revising the article: S Gil-Robles, H Duffau. Reviewed final version of manuscript and approved it for submission: S Gil-Robles, H Duffau. Study supervision: H Duffau.

\section{Acknowledgment}

Thanks to Sara Jaen for her valuable help with the drawings.

\section{References}

1. Bello L, Gambini A, Castellano A, Carrabba G, Acerbi F, Fava E, et al: Motor and language DTI Fiber Tracking combined with intraoperative subcortical mapping for surgical removal of gliomas. Neuroimage 39:369-382, 2008

2. Bello L, Gallucci M, Fava M, Carrabba G, Giussani C, Acerbi $\mathrm{F}$, et al: Intraoperative subcortical language tract mapping guides surgical removal of gliomas involving speech areas. Neurosurgery 60:67-82, 2007

3. Berger MS, Deliganis AV, Dobbins J, Keles GE: The effect of extent of resection on recurrence in patients with low grade cerebral hemisphere gliomas. Cancer 74:1784-1791, 1994

4. Berger MS, Cohen WA, Ojemann GA: Correlation of motor cortex brain mapping data with magnetic resonance imaging. J Neurosurg 72:383-387, 1990

5. Berger MS, Kincaid J, Ojemann GA, Lettich E: Brain mapping techniques to maximize resection, safety, and seizure control in children with brain tumors. Neurosurgery 25:786792, 1989

6. Bertani G, Fava E, Casaceli G, Carrabba G, Casarotti A, Papagno $\mathrm{C}$, et al: Intraoperative mapping and monitoring of brain functions for the resection of low-grade gliomas: technical considerations. Neurosurg Focus 27(4):E4, 2009

7. Bürgel U, Mädler B, Honey CR, Thron A, Gilsbach J, Coenen VA: Fiber tracking with distinct software tools results in a clear diversity in anatomical fiber tract portrayal. Cen Eur Neurosurg 70:27-35, 2009

8. Carrabba G, Fava E, Giussani C, Acerbi F, Portaluri F, Songa $\mathrm{V}$, et al: Cortical and subcortical motor mapping in rolandic and perirolandic glioma surgery: impact on postoperative morbidity and extent of resection. J Neurosurg Sci 51:45-51, 2007

9. Catani M, Thiebaut de Schotten M: A diffusion tensor imaging tractography atlas for virtual in vivo dissections. Cortex 44:1105-1132, 2008

10. Claus EB, Horlacher A, Hsu L, Schwartz RB, Dello-Iacono D, Talos F, et al: Survival rates in patients with low-grade glioma after intraoperative magnetic resonance image guidance. Cancer 103:1227-1233, 2005

11. Desmurget M, Bonnetblanc F, Duffau H: Contrasting acute and slow-growing lesions: a new door to brain plasticity. Brain 130:898-914, 2007

12. Duffau H: Does post-lesional subcortical plasticity exist in the human brain? Neurosci Res 65:131-135, 2009

13. Duffau H. Surgery of low-grade gliomas: toward a 'functional neurooncology'. Curr Opin Oncol [epub ahead of print], 2009

14. Duffau H, Peggy Gatignol ST, Mandonnet E, Capelle L, Taillandier L: Intraoperative subcortical stimulation mapping of language pathways in a consecutive series of 115 patients with Grade II glioma in the left dominant hemisphere. J Neurosurg 109:461-471, 2008

15. Duffau H: The anatomo-functional connectivity of language revisited. New insights provided by electrostimulation and tractography. Neuropsychologia 46:927-934, 2008

16. Duffau H: Brain plasticity and tumors. Adv Tech Stand Neurosurg 33:3-33, 2008

17. Duffau H: Contribution of cortical and subcortical electrostimulation in brain glioma surgery: methodological and functional considerations. Neurophysiol Clin 37:373-382, 2007

18. Duffau H: Brain plasticity: from pathophysiological mechanisms to therapeutic applications. J Clin Neurosci 13:885897,2006

19. Duffau H: Lessons from brain mapping in surgery for lowgrade glioma: insights into associations between tumour and brain plasticity. Lancet Neurol 4:476-486, 2005

20. Duffau H, Lopes M, Arthuis F, Bitar A, Sichez JP, Van Effenterre R, Capelle L: Contribution of intraoperative electrical stimulations in surgery of low grade gliomas: a comparative study between two series without (1985-96) and with (19962003) functional mapping in the same institution. J Neurol Neurosurg Psychiatry 76:845-51, 2005

21. Duffau H, Gatignol P, Mandonnet E, Peruzzi P, Tzourio-Mazoyer N, Capelle L: New insights into the anatomo-functional connectivity of the semantic system: a study using corticosubcortical electrostimulations. Brain 128:797-810, 2005

22. Duffau H, Gatignol P, Denvil D, Lopes M, Capelle L: The articulatory loop: study of the subcortical connectivity by electrostimulation. Neuroreport 14:2005-2008, 2003

23. Duffau H, Capelle L, Denvil D, Sichez N, Gatignol P, Taillandier L, et al: Usefulness of intraoperative electrical subcortical mapping during surgery for low-grade gliomas located within eloquent brain regions: functional results in a consecutive series of 103 patients. J Neurosurg 98:764-778, 2003

24. Duffau H, Capelle L, Sichez N, Denvil D, Lopes M, Sichez JP, et al: Intraoperative mapping of the subcortical language pathways using direct stimulations. An anatomo-functional study. Brain 125:199-214, 2002

25. Duffau H: Recovery from complete hemiplegia following resection of a retrocentral metastasis: the prognostic value of in- 
traoperative cortical stimulation. J Neurosurg 95:1050-1052, 2001

26. Duffau H. Acute functional reorganization of the human motor cortex during resection of central lesions: a study using intraoperative brain mapping. J Neurol Neurosurg Psychiatry 70:506-513, 2001

27. Fandino J, Kollias SS, Wieser HG, Valavanis A, Yonekawa Y: Intraoperative validation of functional magnetic resonance imaging and cortical reorganization patterns in patients with brain tumors involving the primary motor cortex. J Neurosurg 91:238-250, 1999

28. Fernández-Miranda JC, Rhoton AL Jr, Alvarez-Linera J, Kakizawa Y, Choi C, de Oliveira EP: Three-dimensional microsurgical and tractographic anatomy of the white matter of the human brain. Neurosurgery 62 (6 Suppl 3):989-1028, 2008

29. FitzGerald DB, Cosgrove GR, Ronner S, Jiang H, Buchbinder BR, Belliveau JW, et al: Location of language in the cortex: a comparison between functional MR imaging and electrocortical stimulation. AJNR Am J Neuroradiol 18:1529-1539, 1997

30. Gehring K, Sitskoorn MM, Gundy CM, Sikkes SA, Klein M, Postma TJ, et al: Cognitive rehabilitation in patients with gliomas: a randomized, controlled trial. J Clin Oncol 27:3712-3722, 2009

31. Gil Robles S, Gatignol P, Capelle L, Mitchell MC, Duffau $\mathrm{H}$ : The role of dominant striatum in language: a study using intraoperative electrical stimulations. J Neurol Neurosurg Psychiatry 76:940-946, 2005

32. Grummich P, Nimsky C, Pauli E, Buchfelder M, Ganslandt O: Combining fMRI and MEG increases the reliability of presurgical language localization: a clinical study on the difference between and congruence of both modalities. Neuroimage 32:1793-1803, 2006

33. Haglund MM, Berger MS, Shamseldin M, Lettich E, Ojemann GA: Cortical localization of temporal lobe language sites in patients with gliomas. Neurosurgery 34:567-576, 1994

34. Havel P, Braun B, Rau S, Tonn JC, Fesl G, Brückmann H, et al: Reproducibility of activation in four motor paradigms. An fMRI study. J Neurol 253:471-476, 2006

35. Kamada K, Houkin K, Takeuchi F, Ishii N, Ikeda J, Sawamura Y, et al: Visualization of the eloquent motor system by integration of MEG, functional, and anisotropic diffusionweighted MRI in functional neuronavigation. Surg Neurol 59:352-362, 2003

36. Keles GE, Lundin DA, Lamborn KR, Chang EF, Ojemann G, Berger MS: Intraoperative subcortical stimulation mapping for hemispherical perirolandic gliomas located within or adjacent to the descending motor pathways: evaluation of morbidity and assessment of functional outcome in 294 patients. J Neurosurg 100:369-375, 2004

37. Kim PE, Singh M: Functional magnetic resonance imaging for brain mapping in neurosurgery. Neurosurg Focus 15(1):E1, 2003

38. Krishnan R, Raabe A, Hattingen E, Szelényi A, Yahya H, Hermann E, et al: Functional magnetic resonance imaging-integrated neuronavigation: correlation between lesion-to-motor cortex distance and outcome. Neurosurgery 55:904-915, 2004

39. Leclercq D, Duffau H, Delmaire C, Capelle L, Gatignol P, Ducros M, et al: Comparison of diffusion tensor imaging tractography of language tracts and intraoperative subcortical stimulations. J Neurosurg [epub ahead of print], 2009

40. Lehéricy S, Duffau H, Cornu P, Capelle L, Pidoux B, Carpentier A, et al: Correspondence between functional magnetic resonance imaging somatotopy and individual brain anatomy of the central region: comparison with intraoperative stimulation in patients with brain tumors. J Neurosurg 92:589-598, 2000

41. Mandonnet E, Gatignol P, Duffau H: Evidence for an occipito- temporal tract underlying visual recognition in picture naming. Clin Neurol Neurosurg 111:601-605, 2009

42. Mandonnet E, Winkler PA, Duffau H: Direct electrical stimulation as an input gate into brain functional networks: principles, advantages and limitations. Acta Neurochir (Wien) [epub ahead of print], 2009

43. Mandonnet E, Pallud J, Clatz O, Taillandier L, Konukoglu E, Duffau H, et al: Computational modeling of the WHO Grade II glioma dynamics: principles and applications to management paradigm. Neurosurg Rev 31:263-269, 2008

44. Mandonnet E, Delattre JY, Tanguy ML, Swanson KR, Carpentier AF, Duffau $\mathrm{H}$, et al: Continuous growth of mean tumor diameter in a subset of grade II gliomas. Ann Neurol 53:524-528, 2003

45. Martino J, Brogna C, Robles SG, Vergani F, Duffau H. Anatomical dissection of the inferior fronto-occipital fasciculus revisited in the lights of brain stimulation data. Cortex [epub ahead of print], 2009

46. Martino J, Taillandier L, Moritz-Gasser S, Gatignol P, Duffau $\mathrm{H}$ : Re-operation is a safe and effective therapeutic strategy in recurrent WHO Grade II gliomas within eloquent areas. Acta Neurochir (Wien) 151:427-436, 2009

47. McGirt MJ, Chaichana KL, Gathinji M, Attenello FJ, Than K, Olivi A, et al: Independent association of extent of resection with survival in patients with malignant brain astrocytoma. J Neurosurg 110:156-162, 2009

48. Nimsky C, Ganslandt O, Buchfelder M, Fahlbusch R: Intraoperative visualization for resection of gliomas: the role of functional neuronavigation and intraoperative 1.5 T MRI. Neurol Res 28:482-487, 2006

49. Ojemann G, Ojemann J, Lettich E, Berger M: Cortical language localization in left, dominant hemisphere. An electrical stimulation mapping investigation in 117 patients. J Neurosurg 71:316-326, 1989

50. Ojemann G, Mateer C: Human language cortex: localization of memory, syntax, and sequential motor-phoneme identification systems. Science 205:1401-1403, 1979

51. Ojemann GA, Dodrill CB: Verbal memory deficits after left temporal lobectomy for epilepsy. Mechanism and intraoperative prediction. J Neurosurg 62:101-107, 1985

52. Ojemann GA: Models of the brain organization for higher integrative functions derived with electrical stimulation techniques. Hum Neurobiol 1:243-249, 1982

53. Ojemann GA: Individual variability in cortical localization of language. J Neurosurg 50:164-169, 1979

54. Ojemann JG, Ojemann GA, Lettich E: Cortical stimulation mapping of language cortex by using a verb generation task: effects of learning and comparison to mapping based on object naming. J Neurosurg 97:33-38, 2002

55. Penfield W: Thoughts on the function of the temporal cortex. Clin Neurosurg 4:21-33, 1956

56 Penfield W: Combined regional and general anesthesia for craniotomy and cortical exploration. I. Neurosurgical considerations. Curr Res Anest Analg 33:145-155, 1954

57. Penfield W, Welch K: The supplementary motor area of the cerebral cortex; a clinical and experimental study. AMA Arch Neurol Psychiatry 66:289-317, 1951

58. Penfield W, Welch K: Instability of response to stimulation of the sensorimotor cortex of man. J Physiol 109:358-365, 1949

59. Piepmeier JM: Current concepts in the evaluation and management of WHO Grade II gliomas. J Neurooncol 92:253259, 2009

60. Quiñones-Hinojosa A, Ojemann SG, Sanai N, Dillon WP, Berger MS: Preoperative correlation of intraoperative cortical mapping with magnetic resonance imaging landmarks to predict localization of the Broca area. J Neurosurg 99:311-318, 2003

61. Rhoton AL Jr: The cerebrum. Anatomy. Neurosurgery 61 (1 Suppl):37-119, 2007 
62. Robles SG, Gatignol P, Lehéricy S, Duffau H: Long-term brain plasticity allowing a multistage surgical approach to World Health Organization Grade II gliomas in eloquent areas. J Neurosurg 109:615-624, 2008

63. Roux FE, Boulanouar K, Lotterie JA, Mejdoubi M, LeSage JP, Berry I: Language functional magnetic resonance imaging in preoperative assessment of language areas: correlation with direct cortical stimulation. Neurosurgery 52:1335-1347, 2003

64. Rutten GJ, Ramsey NF, van Rijen PC, Noordmans HJ, van Veelen CW: Development of a functional magnetic resonance imaging protocol for intraoperative localization of critical temporoparietal language areas. Ann Neurol 51:350-360,

65. Sanai N, Berger MS: Operative techniques for gliomas and the value of extent of resection. Neurotherapeutics 6:478-486, 2009

66. Sanai N, Berger MS: Glioma extent of resection and its impact on patient outcome. Neurosurgery 62: 264-266, 753-764, 2008

67. Sanai N, Mirzadeh Z, Berger MS: Functional outcome after language mapping for glioma resection. N Engl J Med 358:18-27, 2008

68. Sanai N, Berger MS: Mapping the horizon: techniques to optimize tumor resection before and during surgery. Clin Neurosurg 55:14-19, 2008

69. Signorelli F, Guyotat J, Elisevich K, Barbagallo GM: Review of current microsurgical management of insular gliomas. Acta Neurochir (Wien) [epub ahead of print], 2009

70. Smith JS, Chang EF, Lamborn KR, Chang SM, Prados MD, Cha S, et al: Role of extent of resection in the long-term outcome of low-grade hemispheric gliomas. J Clin Oncol 26:1338-1345, 2008

71. Teixidor P, Gatignol P, Leroy M, Masuet-Aumatell C, Capelle L, Duffau H: Assessment of verbal working memory before and after surgery for low-grade glioma. J Neurooncol 81:305-313, 2007

72. Thiebaut de Schotten M, Urbanski M, Duffau H, Volle E, Lévy R, Dubois B, et al: Direct evidence for a parietal-frontal pathway subserving spatial awareness in humans. Science 309:2226-2228, 2005. Erratum in Science 317:597, 2007

73. Wilkinson ID, Romanowski CA, Jellinek DA, Morris J, Griffiths PD: Motor functional MRI for pre-operative and intraoperative neurosurgical guidance. Br J Radiol 76:98-103, 2003

Manuscript submitted October 12, 2009.

Accepted December 10, 2009.

Address correspondence to: Santiago Gil-Robles, M.D., Department of Neurosurgery, Hospital Quiron, Calle Diego de Velazquez 1, 28223 Pozuelo de Alarcón, Madrid, Spain. email: santigilrob@yahoo.es. 